The Texas Medical Center Library

DigitalCommons@TMC

The University of Texas MD Anderson Cancer Center UTHealth Graduate School of

Biomedical Sciences Dissertations and Theses

(Open Access)
The University of Texas MD Anderson Cancer

Center UTHealth Graduate School of

Biomedical Sciences

\title{
Attitudes Toward and Uptake of Prenatal Genetic Screening and Testing in Twin Pregnancies
}

Kathryn M. Reese

Follow this and additional works at: https://digitalcommons.library.tmc.edu/utgsbs_dissertations

Part of the Genetics Commons, and the Medicine and Health Sciences Commons

\section{Recommended Citation}

Reese, Kathryn M., "Attitudes Toward and Uptake of Prenatal Genetic Screening and Testing in Twin Pregnancies" (2017). The University of Texas MD Anderson Cancer Center UTHealth Graduate School of Biomedical Sciences Dissertations and Theses (Open Access). 765.

https://digitalcommons.library.tmc.edu/utgsbs_dissertations/765

This Thesis (MS) is brought to you for free and open access by the The University of Texas MD Anderson Cancer Center UTHealth Graduate School of Biomedical Sciences at DigitalCommons@TMC. It has been accepted for inclusion in The University of Texas MD Anderson Cancer Center UTHealth Graduate School of Biomedical Sciences Dissertations and Theses (Open Access) by an authorized administrator of DigitalCommons@TMC. For more information, please contact digitalcommons@library.tmc.edu.

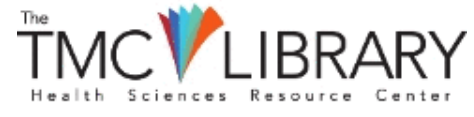


ATTITUDES TOWARD AND UPTAKE OF PRENATAL GENETIC SCREENING AND TESTING IN TWIN PREGNANCIES

\author{
by
}

Kathryn M. Reese, BS

\title{
APPROVED:
}

Claire Singletary, MS, CGC Advisory Professor

Jennifer Czerwinski, MS, CGC

Sandra Darilek, MS, CGC

Anthony Johnson, DO

Malorie Jones, MS, CGC

APPROVED:

Dean, The University of Texas

MD Anderson Cancer Center UTHealth Graduate School of Biomedical Sciences 


\title{
ATTITUDES TOWARD AND UPTAKE OF PRENATAL GENETIC SCREENING AND TESTING IN TWIN PREGNANCIES
}

\author{
A \\ THESIS \\ Presented to the Faculty of \\ The University of Texas \\ MD Anderson Cancer Center UTHealth \\ Graduate School of Biomedical Sciences \\ in Partial Fulfillment \\ of the Requirements \\ for the Degree of \\ MASTER OF SCIENCE \\ by \\ Kathryn M. Reese, BS \\ Houston, Texas
}

May, 2017 


\title{
ATTITUDES TOWARD AND UPTAKE OF PRENATAL GENETIC SCREENING AND TESTING IN TWIN PREGNANCIES
}

\author{
Kathryn M. Reese, BS
}

Advisory professor: Claire Singletary, MS

The rate of twinning is rising and is associated with delayed age at childbirth and increased infertility treatments. Since the introduction of noninvasive prenatal testing, interest in and uptake of genetic screening and testing in twin pregnancies has not been investigated. Therefore, this study aimed to describe the attitudes toward and uptake of current prenatal genetic screening and testing options in twin pregnancies. Forty-two women with twin gestations were recruited from UTHealth and Baylor College of Medicine sites between August 2016 and January 2017 for participation in a descriptive study consisting of a questionnaire $(n=42)$ and semi-structured phone interview $(n=15)$. Descriptive statistics and Fischer's exact-test were employed for questionnaire analysis. Qualitative data from interviews were analyzed using grounded-theory to identify common themes. Data analysis showed that women were significantly more in favor of screening than diagnostic testing $(\mathrm{p}=0.049)$. Sixty-nine percent elected genetic screening, while only three percent had a diagnostic procedure. Women were interested in screening for preparation or reassurance despite having concerns about accuracy and uncertainty associated with screening in twin pregnancies. Most women (86\%) felt they would make the same decision if it were a singleton pregnancy, suggesting that twin pregnancy may not impact decision-making for many women. Despite this, $48 \%$ of women still cited being pregnant with twins as an influencing 
factor. Information learned from medical providers, past experiences, and family and friends were also cited as influencing factors, suggesting that tailoring prenatal genetic counseling sessions for twin gestations might parallel that of singletons. Although it did not alter patient decisions for $91 \%$ of women, genetic counseling was used as a platform to raise concerns and gather information. No significant differences between natural and assisted conception patients were found; however, further research in this area is necessary given the small sample size. 


\section{TABLE OF CONTENTS}

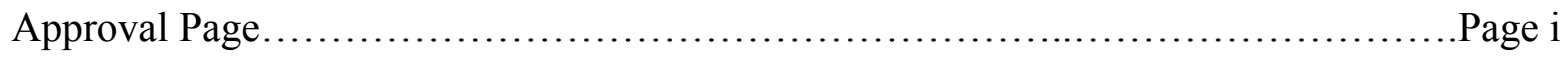

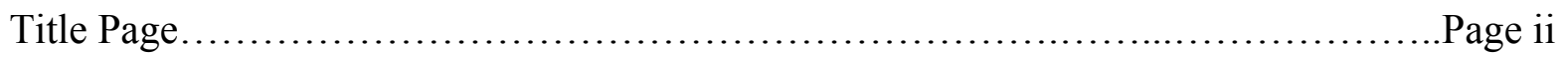

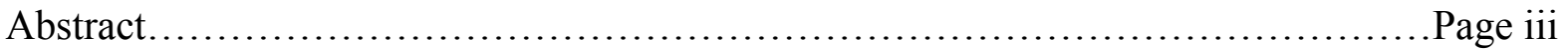

Table of Contents......................................................... $v$

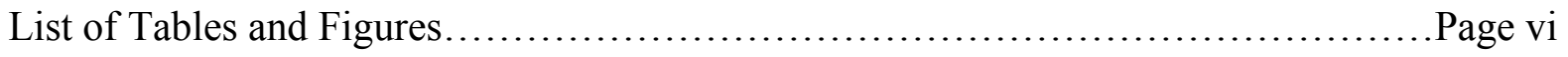

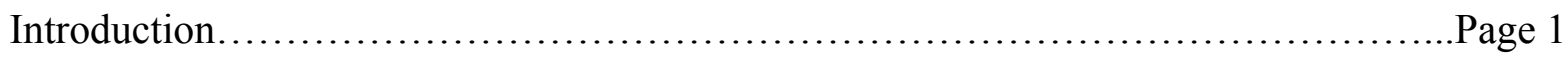

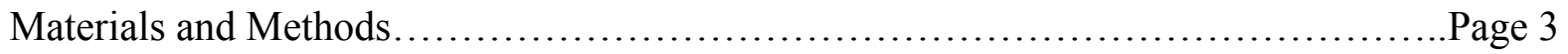

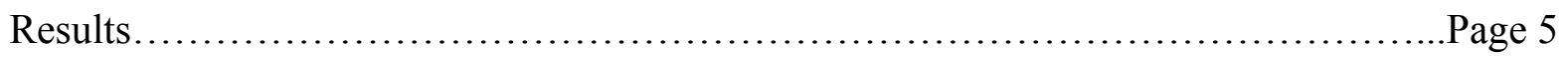

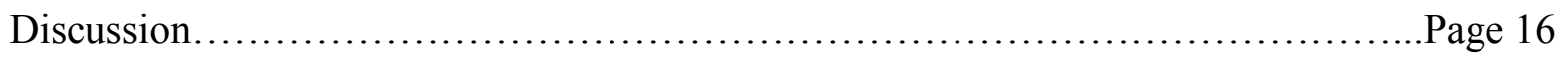

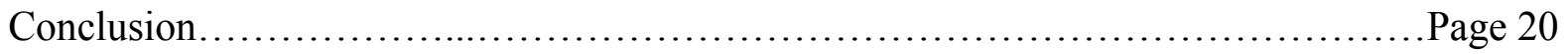

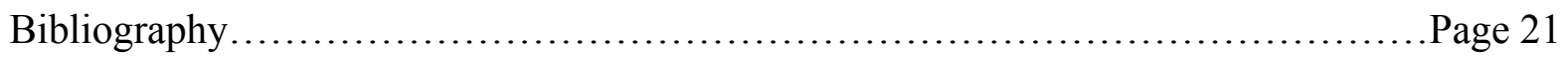

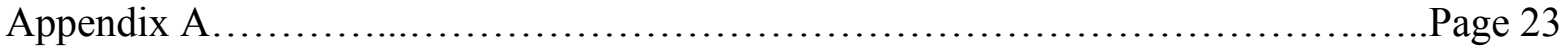

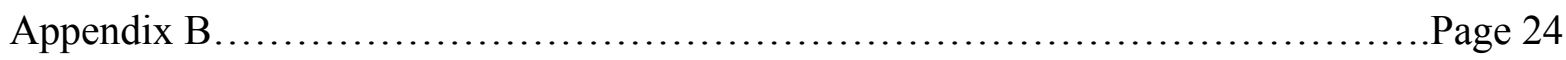

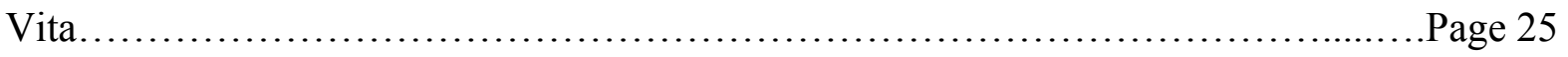




\section{LIST OF TABLES AND FIGURES}

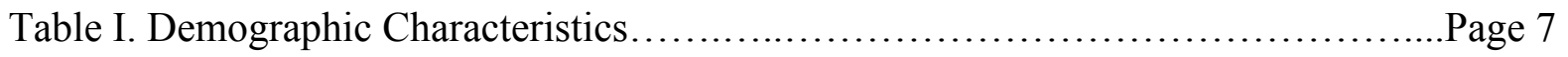

Figure 1. Attitudes toward screening vs. diagnostic testing........................... 8

Table II. Interest in Prenatal Genetic Screening and/or Testing......................Page 10

Table III. Concerns about Prenatal Genetic Screening and/or Testing.....................Page 12

Table IV. Factors influencing decision-making ........................................ege 14

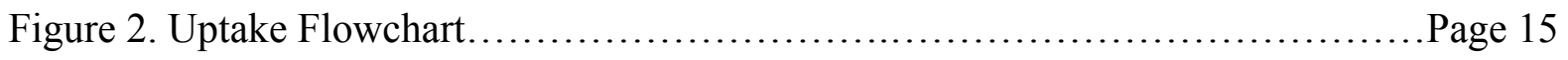

Figure 3. Influence of twin pregnancy on uptake...................................age 16 


\section{INTRODUCTION}

Genetic counselors may become involved in the prenatal care of women carrying twins due to delayed childbirth and subsequent advanced maternal age (AMA) among other indications. AMA is a common referral for prenatal genetic counseling and is defined as a woman who will be 35 years or older at the time of delivery in a singleton pregnancy. However, many clinicians use 31 or 33 years or older as AMA for twin pregnancies due to the comparable risk for aneuploidy in at least one fetus (1).

According to data from the U.S. Department of Health and Human Services, the twin birth rate was 33.9 per 1,000 births in 2014 . This rate rose $76 \%$ from 1980 to 2009 and then rose an additional two percent by 2013. Increasing twin birth rates have been associated with trends of delayed age at childbirth and increased use and availability of infertility treatments compared to previous decades (2). The American Society for Reproductive Medicine (ASRM) defines assisted reproductive technology (ART) as treatments and procedures involving the handling of human oocytes and sperm, or embryos, with the intent of establishing pregnancy (3). ART has been used in the US since 1981 and today, $1 \%$ of all infants born are conceived using ART. Women who undergo ART procedures are more likely to have multiple gestations than women who conceive naturally.

The psychosocial impact of infertility and ART has been linked to distress, loss of control, stigmatization, and a feeling of disruption in the way women viewed their life to go (4). Some stressors experienced include infertility itself, inconvenience associated with treatment, perception of a low success rate, time spent waiting for results, as well as financial pressure (5). 
Whether conceived naturally or through ART, once women achieve a pregnancy, they are faced with decisions about screening and testing. Genetic counselors often act as facilitators for decision making about prenatal genetic screening, such as first trimester screen, quadruple screen, or non invasive prenatal testing (NIPT) and diagnostic testing. This is complicated in twin pregnancies because there is relatively little literature on aneuploidy screening in twin pregnancies and conclusions are inconsistent. Detection rates for Down syndrome when using first trimester nuchal translucency (NT) measurement and maternal age are $70-88 \%$ in twin pregnancies, which is similar to that in singleton pregnancies (6). The Down syndrome detection rate of a quadruple marker serum screen is $51-63 \%$ (7) compared to $81 \%$ in singleton pregnancies (8). Diagnostic testing via chorionic villus sampling (CVS) and amniocentesis is also available. The risks with CVS appear to be relatively comparable between singletons and twins. However, the risk for miscarriage after amniocentesis appears higher for twin gestations compared to singletons (9).

In 2011, NIPT became clinically available, providing more prenatal screening options for high-risk pregnancies. NIPT using massively parallel shotgun sequencing (MPSS) technology can be applied to twin gestations and screens for trisomy 21 , trisomy 18 , trisomy 13, and the presence of the $\mathrm{Y}$ chromosome. While detection rate varies by testing laboratory, a meta-analysis in 2015 found a detection rate of $93.7 \%$ for trisomy 21 in twin pregnancies and a false positive rate of $0.23 \%(10)$.

Prior to the availability of NIPT as a screening option, a studied cohort of 343 twin or higher or multiple pregnancies and found a minority (23\%) of patients elected to undergo prenatal genetic screening or testing (11). The authors found that $94 \%$ of the patients who did 
have prenatal genetic screening or testing chose maternal serum screening. It was hypothesized that it may be viewed as less risky than the alternatives while still relieving some anxiety. Furthermore, no relationship was found between the use of ovulation induction (OI) or ART and election of prenatal genetic testing $(11,12)$. However, these studies predate NIPT, a screen with higher sensitivity and specificity. Therefore, this study aimed to describe the uptake of and attitude toward current prenatal genetic screening and testing options in twin pregnancies in order to provide insight into the factors that play a role in the choice to undergo genetic screening or testing.

\section{MATERIALS AND METHODS}

\section{Study Design}

Women having genetic counseling at one of six McGovern Medical School at UTHealth, Department of Obstetrics, Gynecology and Reproductive Sciences, Division of Maternal Fetal Medicine affiliated clinics or one of seven Baylor College of Medicine, Department of Obstetrics and Gynecology affiliated high-risk pregnancy clinics were recruited between August 2016 and January 2017. Eligible women included those who were pregnant with twins, age 18 or older, and English speaking who were seen for prenatal genetic counseling in their current pregnancy. Exclusion criteria included women under the age of 18 , singleton pregnancies, non-English speakers, and twin pregnancies seen in the high-risk fetal center with anomalies excluded at the discretion of the genetic counselor.

Eligible women were given a letter of invitation by the genetic counselor at the conclusion of the genetic counseling appointment. Participants could consent to either the anonymous survey only or the anonymous survey and an additional phone interview. Semistructured interviews were conducted by the study coordinator (KR) via telephone with 
participants who indicated interest and provided contact information. Transcription by the interviewer was performed by listening to recorded audiotapes and transcribing everything spoken by the interviewer and study participant into a protected document.

The institutional review boards at the University of Texas Health Science Center at Houston (HSC-MS-16-0410) and Baylor College of Medicine (H-39711) approved the study protocol.

\section{Data Collection}

Data were collected through in person questionnaires collected immediately following the genetic counseling appointment and via semi-structured telephone interviews within eight weeks of the appointment. The survey collected information about attitudes toward prenatal genetic screening and testing, changes related to the genetic counseling appointment and impact of twin pregnancy on decision-making from participants. Demographic information including age, gravidity and parity, indication for genetic counseling, use of ART, genetic screening/testing offered, and genetic screening/testing accepted was recorded by the genetic counselor (Appendix A). The telephone interviews were conducted by the study coordinator (KR) using an interview guide (Appendix B) and lasted approximately 20 minutes. The telephone interviews were audio taped and transcribed by the interviewer. The study questionnaire and interview guide were created by the authors and were not formally validated.

\section{Data Analysis}

Questionnaire data were entered into a secure Microsoft Excel file and STATA software version 13.1 was used for statistical analysis of quantitative data. Categorical 
variable data were reported as frequencies and percentages and analyzed using two-sample ttest and Fischer's exact test. Transcripts were entered into ATLAS.ti version 1.0.50. Thematic analysis was used to identify major themes in the responses, using the grounded theory approach. Each transcript was coded and grouped into categories that revealed similar themes. The study coordinator (KR) and one author (CS) independently analyzed three transcripts to compare and establish consistency in coding using a preliminary codebook. An inter-coder concordance of $80 \%$ was achieved. KR analyzed the remaining transcripts and grouped responses into themes.

\section{RESULTS}

A total of 42 individuals participated in the study. Of those, 27 (64\%) consented to participate in the phone interview in addition to the questionnaire, while $15(36 \%)$ consented to the questionnaire only. Of the 27 who indicated willingness to participate in the phone interview portion, there were $16(59 \%)$ individuals who completed the interview and 11 (41\%) that could not be reached after multiple attempts. One completed interview was excluded from analysis due to fragmented recording. The average age of study participants was 31 years, with a range from 21 to 47 years old, and the majority were Caucasian (Table I). The majority of participants were multigravida with the most common indications being AMA (43\%) and low risk (38\%). Participants were recruited from Houston-area University of Texas Health Science Center at Houston (UTHealth) and Baylor College of Medicine (Baylor) affiliated clinics. Eleven participants were from UTHealth clinics and 31 were from Baylor clinics, representing $30 \%$ of eligible UTHealth patients (11/37) and $78 \%$ of eligible Baylor patients (31/40) seen for prenatal genetic counseling during the survey collection period. No significant differences in demographic distribution were found between 
participants from the UTHealth and Baylor sites ( $p>0.05$ ), (Table I). Additionally, demographic distribution of the study sample was not significantly different between those who were interviewed and those that only answered the questionnaire ( $p>0.05)$, (Table I). 


\begin{tabular}{|c|c|c|c|c|c|c|c|c|}
\hline Characteristic & \multicolumn{2}{|c|}{$\begin{array}{c}\text { Baylor** } \\
(\mathbf{n}=31)\end{array}$} & \multicolumn{2}{|c|}{$\begin{array}{l}\text { UTHealth** } \\
\quad(\mathbf{n}=11)\end{array}$} & \multicolumn{2}{|c|}{$\begin{array}{c}\text { Interview \& } \\
\text { Survey*** } \\
(n=15)\end{array}$} & \multicolumn{2}{|c|}{$\begin{array}{c}\text { Survey } \\
\text { Only*** } \\
(\mathrm{n}=27)\end{array}$} \\
\hline $\begin{array}{r}\text { Mean Age (years) } \\
\text { Total SD }=5.6\end{array}$ & \multicolumn{2}{|c|}{31.35} & \multicolumn{2}{|c|}{31.27} & \multicolumn{2}{|c|}{30.4} & \multicolumn{2}{|c|}{31.9} \\
\hline & $\mathbf{n}$ & $\%$ & $\mathbf{n}$ & $\%$ & $\mathbf{n}$ & $\%$ & n & $\%$ \\
\hline Ethnicity & & & & & & & & \\
\hline Caucasian & 14 & $45 \%$ & 5 & $46 \%$ & 7 & $47 \%$ & 12 & $44 \%$ \\
\hline Hispanic & 5 & $26 \%$ & 3 & $27 \%$ & 4 & $27 \%$ & 4 & $15 \%$ \\
\hline African American & 8 & $16 \%$ & 1 & $9 \%$ & 2 & $13 \%$ & 7 & $26 \%$ \\
\hline Asian & 4 & $13 \%$ & 1 & $9 \%$ & 1 & $7 \%$ & 4 & $15 \%$ \\
\hline Other & 0 & $0 \%$ & 1 & $9 \%$ & 1 & $7 \%$ & 0 & $0 \%$ \\
\hline \multicolumn{9}{|l|}{ Indication } \\
\hline Low Risk & 11 & $35 \%$ & 5 & $45 \%$ & 8 & $53 \%$ & 8 & $30 \%$ \\
\hline AMA & 12 & $39 \%$ & 6 & $55 \%$ & 5 & $33 \%$ & 13 & $48 \%$ \\
\hline Positive Family History & 1 & $3 \%$ & 0 & $0 \%$ & 0 & $0 \%$ & 1 & $4 \%$ \\
\hline US Abnormality & 3 & $10 \%$ & 0 & $0 \%$ & 1 & $7 \%$ & 2 & $7 \%$ \\
\hline Multiple & 4 & $13 \%$ & 0 & $0 \%$ & 1 & $7 \%$ & 3 & $11 \%$ \\
\hline \multicolumn{9}{|l|}{ Gravidity* } \\
\hline Primigravida & 9 & $29 \%$ & 2 & $18 \%$ & 5 & $33 \%$ & 6 & $22 \%$ \\
\hline Multigravida & 20 & $65 \%$ & 9 & $82 \%$ & 9 & $60 \%$ & 20 & $74 \%$ \\
\hline \multicolumn{9}{|l|}{ Mode of Conception } \\
\hline Natural & 23 & $74 \%$ & 4 & $64 \%$ & 12 & $80 \%$ & 4 & $64 \%$ \\
\hline Assisted & 8 & $26 \%$ & 7 & $36 \%$ & 3 & $20 \%$ & 7 & $36 \%$ \\
\hline
\end{tabular}

*Data missing for 2 participants from Baylor clinics

**All p-values $>\mathbf{0 . 0 5}$ for comparison of UTHealth and Baylor demographics

$* * *$ All p-values $>\mathbf{0 . 0 5}$ for comparison of interview and survey only demographics 


\section{Attitude toward prenatal genetic screening and testing}

Multiple attitudes toward screening and testing were identified. Women carrying twin pregnancies were found to be significantly more likely to be "in favor of" or "strongly in favor of" prenatal genetic screening compared to prenatal diagnostic testing $(p=0.049)$, (Figure 1).

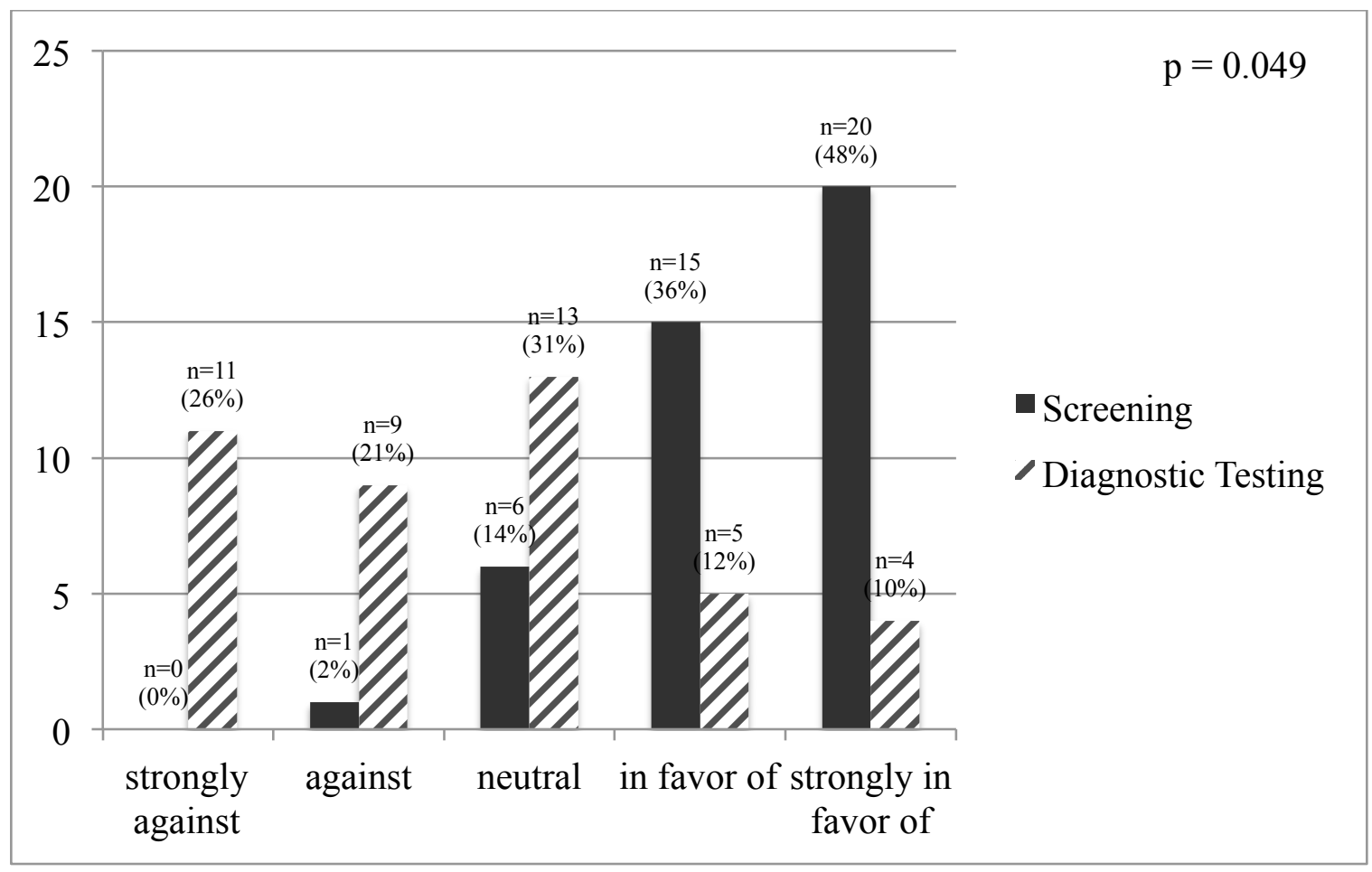

Figure 1. Attitudes toward screening vs. diagnostic testing

Comparing attitudes of those with a natural conception to those with assisted conception revealed no significant difference between the groups $(p>0.05)$. In general, both groups were more in favor of screening than diagnostic testing, with $80 \%$ of those with a natural conception and $92 \%$ of those with assisted conception feeling "in favor of" or "strongly in favor of" prenatal genetic screening. Indication for genetic counseling referral 
was not found to have a significant influence on attitude toward prenatal genetic screening or testing ( $p>0.05$ across indications).

\section{Interest in prenatal genetic screening and/or testing}

Interview respondents reported an overall general interest in prenatal genetic screening and/or testing. Motivations for this interest varied among responses, with the risk of possible abnormalities in the pregnancy being the most commonly used code. One woman indicated "[she's] always scared that [the test] will come back that [they're] carriers of something or [their] risk is higher for something" but that "it's always better to know".

The next most common motivation for interest in prenatal genetic testing was a desire for answers in order to be better prepared, reassured, or have peace of mind. Forty-eight percent of participants selected gaining reassurance about the pregnancy as an influencing factor in the questionnaire. Participants felt that "it's one of those things where [they] would like to be prepared if something was to happen" and that "with twins... [they] need to know what's going on as much as possible". Additional examples of interest in prenatal genetic screening and/or testing can be found in Table II. 
Table II. Interest in prenatal genetic screening and/or testing

\section{Themes Responses}

Concern for Possible

Abnormalities ( $n=19)$
“... like any other woman I was scared that...something would be found "

"I'm a little bit more worried about having children after the age of $34 \ldots$ because of seeing that scale and those percentages of...the baby being affected with the different types of chromosome [conditions]"

\begin{tabular}{|c|c|}
\hline Wanting Answers ( $\mathrm{n}=9$ ) & $\begin{array}{l}\text { "... is there a way for us to find out if we're going to } \\
\text { have a healthy baby or if both babies are going to be } \\
\text { healthy? Then we want to go ahead and do a } \\
\text { prescreening." }\end{array}$ \\
\hline Preparation $(n=7)$ & $\begin{array}{l}\text { "I think it's important to know everything you can before } \\
\text { going into it" }\end{array}$ \\
\hline \multirow[t]{2}{*}{ Reassurance $(n=6)$} & $\begin{array}{l}\text { "I would have done it anyways just to kind of make sure } \\
\text { there weren't any problems }\end{array}$ \\
\hline & $\begin{array}{l}\text { "I just wanted to make sure there wasn't anything that I } \\
\text { need to be worried about as far as like you know the } \\
\text { health of the baby" }\end{array}$ \\
\hline Peace of Mind $(n=3)$ & $\begin{array}{l}\text { "[genetic testing] does have such an ability to bring peace } \\
\text { of mind or to... help parents... plan... get a better idea of } \\
\text { what...they're walking into" }\end{array}$ \\
\hline
\end{tabular}




\section{Concerns about prenatal genetic screening and/or testing}

Respondents also expressed concerns about prenatal genetic screening and/or testing. In some cases, these concerns were strong enough to make the woman not interested in screening or testing. The most common concern was for the risks posed to the pregnancy as one woman expressed in her statement "I would've rather not taken that risk of losing them than trying to figure out if something was wrong with them". An interview with a woman who conceived via IVF revealed substantial concern about invasive testing due to associated risks. She said that she felt she "worried more about loss... than if [conception] had happened easily" and that she knew "it's not going to be easy... if [they] needed to start over". Additional concerns included cost, anxiety, uncertainty, and accuracy of screening (Table III).

Overall, codes associated with concern about prenatal genetic screening and/or testing were used more frequently $(n=171)$ than codes associated with interest in prenatal genetic screening and/or testing $(\mathrm{n}=99)$. 
Table III. Concerns about prenatal genetic screening and/or testing

Themes

Risks to Pregnancy $(\mathrm{n}=19)$

\section{Responses}

“... invasive stuff comes with risks...I definitely didn't really want to do those unless there was... a high, high risk of some abnormalities"

"... but as far as the other options, [FTS] felt like safer, like a safer option"

"I would've rather not taken that risk on losing them then trying to figure out if something was wrong with them"

\begin{tabular}{|c|c|}
\hline Cost $(n=16)$ & $\begin{array}{l}\text { "... with the cost involved, I wouldn't have done it even } \\
\text { for one [baby]" }\end{array}$ \\
\hline & $\begin{array}{l}\text { "I had some friends say no don't do it it's kind of a waste } \\
\text { of money." }\end{array}$ \\
\hline & $\begin{array}{l}\text { "But it wasn't covered by my insurance and I'm already } \\
\text { paying a lot" }\end{array}$ \\
\hline & $\begin{array}{l}\text { "If money wasn't something that was obviously sitting } \\
\text { there staring me right in the face... we would have } \\
\text { absolutely gone ahead with the genetic testing." }\end{array}$ \\
\hline Fear and Anxiety $(\mathrm{n}=18)$ & $\begin{array}{l}\text { "I had a lot of anxiety about the pregnancy as it is... } \\
\text { testing is... another thing to be anxious about." }\end{array}$ \\
\hline & "I was actually pretty scared and nervous." \\
\hline Uncertainty $(n=9)$ & $\begin{array}{l}\text { "I think with fraternal, I'd always wonder... which twin it } \\
\text { came from and... worry about it that way" }\end{array}$ \\
\hline & $\begin{array}{l}\text { "... we didn't know really what the sort of accuracy rates } \\
\text { were... or many of the specifics of... how the } \\
\text { information, how the results are delivered" }\end{array}$ \\
\hline $\begin{array}{l}\text { Concern about Accuracy } \\
(\mathrm{n}=10)\end{array}$ & $\begin{array}{l}\text { "... it sounds like the accuracy is higher with just one } \\
\text { baby than it is with two. So I think then we might have } \\
\text { been more willing to do it" }\end{array}$ \\
\hline & $\begin{array}{l}\text { "...if there was only one we might have been more open } \\
\text { to it but since there was two... and the accuracy is not as } \\
\text { high, we were less inclined" }\end{array}$ \\
\hline
\end{tabular}




\section{Factors influencing decision-making}

Respondents indicated that information gathering was an important factor in decisionmaking $(n=46)$ both from information they learned in the genetic counseling session and outside of the session. For example, one woman said that "if anything, [the genetic counselor] gave [them] information to actually formulate opinions."

Experiences in previous pregnancies and experiences of friends and family members were cited as influencing factors $(\mathrm{n}=37)$. One woman said, "it's one of those things... [they've] historically done just the... standard first trimester screen”. Additionally, input of support persons such as partners or spouses played a role in women's decisionmaking. One woman said that she and her husband "weighed out the pros and cons" and that he was a "major factor in it... and helped decide if [they] were going to do it or not". Two of the most common factors selected in the questionnaire as having influenced participant's decisions included being pregnant with twins (48\%) and their partner/spouse (43\%). Additional examples of factors influencing decision-making can be found in Table IV. 
Table IV. Factors influencing decision-making

\section{Themes Responses}

Information Gathering $(\mathrm{n}=46) \quad$ "... they just wanted to let me be aware of... there's a $99 \%$ chance, sure that there is nothing wrong with them"

"I felt more aware, I got more... information I guess. I got more aware of what possibilities of what could be happening"

"I would say that the only thing that the counselor kind of affected for was like looking at those charts and seeing... the percentage of risk based on the age"

“... she broke everything down, you know, and explained... all of our options"

Prior Experience and Knowledge $(n=37)$
"... the test that we chose and doing that with my last son, him being perfectly fine then I was pretty much at ease with doing the same test"

“... my cousin got the [amniocentesis]... she wanted to know and she ended up losing her kids cause of the infection"

"I was seen by the same doctor with... all my three children... But I was never offered... so I didn't even know you had those kind of testing"

\section{Support Persons $(\mathrm{n}=2)$}

“... my husband. I asked him what he thought and he said yeah let's just do the same test we did with my son" "... my mom... went with me... she was the one who... guided me in the decision making process."

“... my mom said that she never got any of that testing done but I just don't think it was available at the time. I don't know what she would have done now." 


\section{Uptake of prenatal genetic screening and testing}

There was no significant difference in uptake of prenatal genetic screening and testing between natural and assisted conception women $(\mathrm{p}=0.48)$. When asked about whether or not their decision about prenatal genetic screening or testing agreed with their feelings prior to the genetic counseling appointment, $91 \%$ answered that it did agree. Additionally, $86 \%$ of women answered that their decision about prenatal genetic screening and testing would have been the same if it were a singleton pregnancy. Of the 41 women offered a prenatal genetic screening or diagnostic test, $39 \%$ declined all testing. Of the 36 women offered prenatal genetic screening (first trimester screen, quadruple screen, NIPT), 69\% accepted. Of the 39 women offered diagnostic genetic testing (chorionic villus sampling, amniocentesis), one individual accepted (Figure 2).

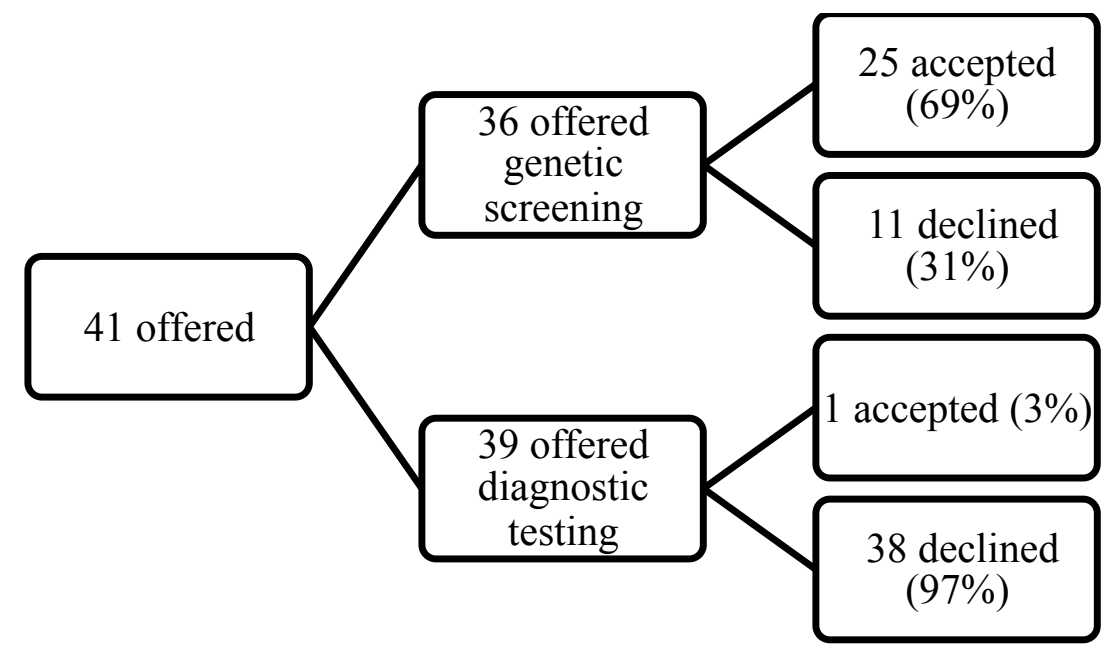

Figure 2. Uptake Flowchart

Individuals who accepted a screening test had attitudes that were generally more "strongly in favor of" screening (56\%) compared to those that declined screening tests $(18 \%)$; however, the overall difference in attitudes was not significant $(\mathrm{p}=0.053)$. Those 
who accepted a prenatal genetic screening test were significantly more likely to say that they would make the same decision if it were a singleton pregnancy $(\mathrm{p}=0.030)$, (Figure 3$)$. All four of the women who indicated that they would make a different decision about prenatal genetic screening or testing in the pregnancy if it were a singleton were also a part of the $48 \%$ of women who selected being pregnant with twins as having influenced decisions.

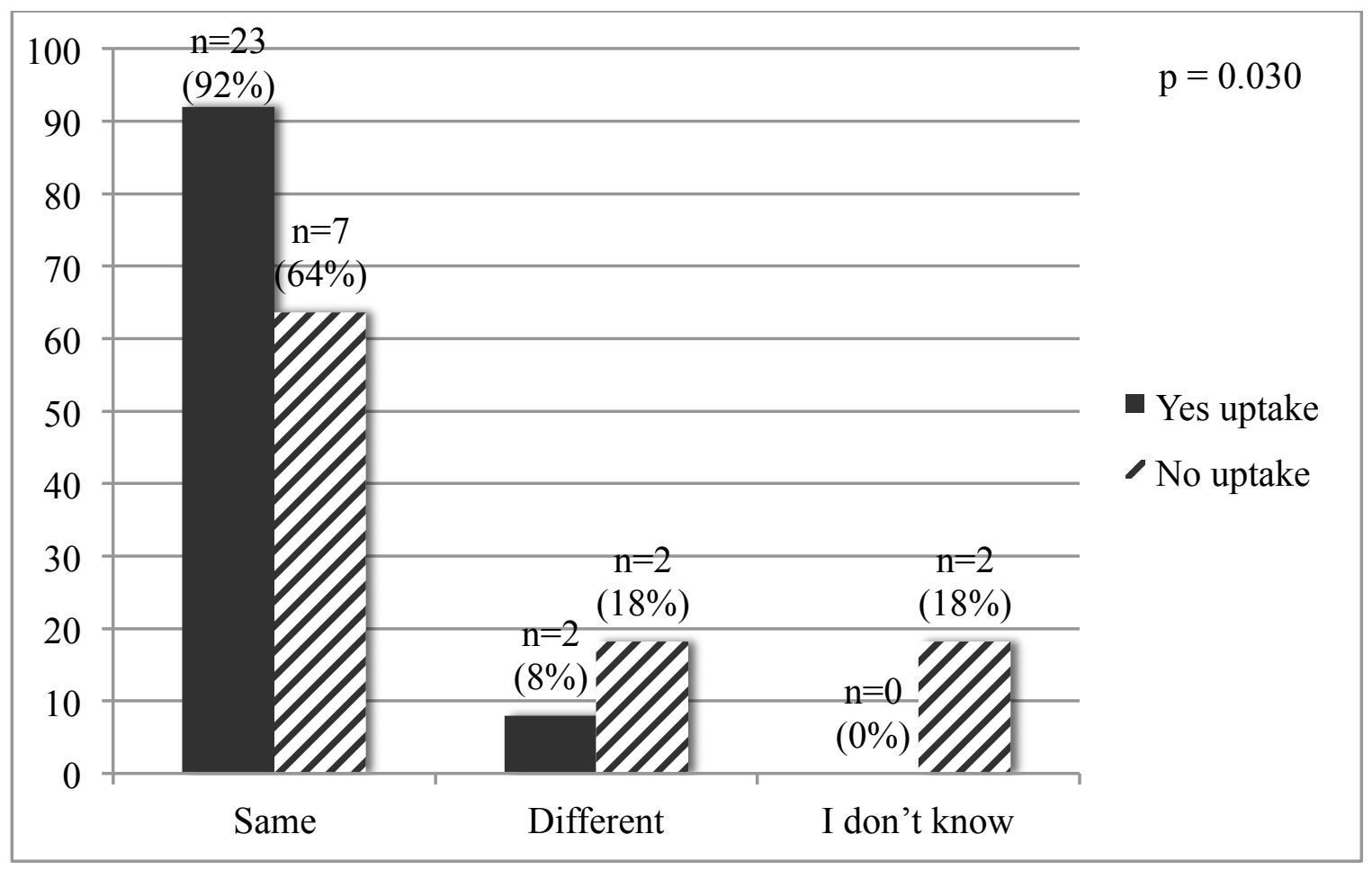

Figure 3. Influence of twin pregnancy on screening uptake

\section{DISCUSSION}

To our knowledge, this is the first study exploring the attitudes toward and uptake of prenatal genetic screening and testing in twin gestations since the advent of NIPT. As anticipated from increasing trends toward screening in singleton pregnancies since the introduction of NIPT, we found that women carrying twins were more likely to be in favor of 
prenatal genetic screening compared to diagnostic testing (13). The risk of diagnostic testing appeared to be a deterrent for some, as seen in previous studies (14). Women communicated a desire to have answers to be better prepared or for reassurance. Attitudes did not differ depending on whether women conceived twin pregnancies naturally or through assisted conception methods. Despite participants being in favor of screening, concerns and barriers were more frequently discussed than interest. In these cases, genetic counseling was used as a platform to relay these concerns and gather additional information about screening and testing, empowering women to make a decision. It appears as though the genetic counseling process made women feel more comfortable with their decision rather than altering it, although future research is needed to capture both pre and post counseling feelings in order to confirm this finding.

Our cohort did elect to undergo screening or testing more often (61\%) than a 2006 cohort of 343 twin or higher or multiple pregnancies (23\%), (11). It is possible that this difference can be explained by the availability of NIPT, since the higher detection rate and lower false positive rate compared to older screens may have lessened concerns. Given that detection rates are even higher in singletons, those who elected to undergo screening might have done so regardless of twin gestation.

The majority of women said they would make the same decision if they had a singleton pregnancy, suggesting that having twins was not an influencing factor. This finding is contradictory to the finding that "being pregnant with twins" was the most commonly cited factor in interviews influencing their decision-making. Perhaps those that did not uptake any screening or testing were more influenced by twin pregnancy. In fact, the women who indicated that they would make a different decision about prenatal genetic screening or 
testing in the pregnancy if it were a singleton were a part of the $48 \%$ of women who selected being pregnant with twins as having influenced decisions. They may have recognized an additional layer of complexity involved in screening and testing for twins. Genetic counselors have the skill set to uncover which women are concerned about this complexity, encourage discussion, and assist in decision-making.

The process of genetic counseling did not appear to ultimately change decisions about prenatal genetic screening and testing for most women, although interview responses indicated that patients do find it helpful and informative. Information gathering about genetic screening and testing takes place in multiple settings, including medical appointments, past personal experience, and the experiences of family and friends. It is possible that anchoring, the concept that people's decisions are most influenced by their initial experiences and knowledge, can explain the why the majority of women reported that genetic counseling did not change their initial impression of genetic screening and testing (15). The anchoring heuristic has been previously explored in genetic counseling decision-making, with positive attitude towards genetic testing being one of the determining factors predicting intent to undergo testing (16). While patients say they are open to learning more information, anchors appear to play an important role in prenatal genetic counseling.

\section{Practice Implications}

This study provides insight into the attitudes toward prenatal genetic screening and testing in women carrying twin pregnancies in an effort to assist in the tailoring of sessions for this patient population. Data suggest that tailoring sessions for twin gestations might parallel that of singletons. Anticipating concerns about risks, cost, uncertainty, and 
accuracy surrounding testing options might make facilitation of decision-making easier and uncover those patients for whom the complexity alters their decision. However, it is not likely to change the majority of patient's attitudes set by personal anchors.

\section{Study Limitations}

The small sample size was a major limitation of the current study, as this impacted the ability to make comparisons between those with natural and assisted conceptions in the interview portion. A longer recruitment time frame might increase sample size enough to achieve statistical significance. Another limitation was the limited demographic information collected, as the influence of socioeconomic status, education level, or religious affiliation on decision-making could not be explored.

Of note, the interviews did not take place at the same duration after the genetic counseling appointment for all participants. Some individuals could not be reached for over a month, and it is possible that the length of time since the genetic counseling appointment altered their attitude and responses. In addition, participants who had stronger attitudes toward prenatal genetic screening and testing may have felt compelled to share their perspectives and thus led to an ascertainment bias.

\section{Future Directions}

Additional studies with larger cohorts should be undertaken in order to determine if there are in fact differences between the natural and assisted conception groups on qualitative section of the questionnaire. In addition, including a singleton matched comparison group could provide more insight into potential differences. 


\section{CONCLUSION}

The majority of women with twin gestations were in favor of and opted into prenatal genetic screening, despite expressing concerns. Most did not feel that their decision would vary if they had been carrying a singleton, suggesting that tailoring genetic counseling for twin gestations might be similar to that of singletons. Genetic counselors have the skill set to uncover which women belong to the minority who are concerned about the complexity of screening in twins and to assist in decision-making. 


\section{BIBLIOGRAPHY}

1. Meyers C, Adam R, Dungan J, Prenger V. 1997. Aneuploidy in twin gestations: when is maternal age advanced? Obstet Gynecol 89: 248-51

2. Hamilton BE, Martin JA, Osterman MJ, Curtin SC, Matthews TJ. 2015. Births: Final Data for 2014. Natl Vital Stat Rep 64: 1-64

3. Practice Committee of the Society for Assisted Reproductive T, the American Society for Reproductive M. 2004. Guidelines on the number of embryos transferred. Fertil Steril 82 Suppl 1: S1-2

4. Cousineau TM, Domar AD. 2007. Psychological impact of infertility. Best Pract Res Clin Obstet Gynaecol 21: 293-308

5. Sanders KA, Bruce NW. 1999. Psychosocial stress and treatment outcome following assisted reproductive technology. Hum Reprod 14: 1656-62

6. Matias A, Montenegro N, Blickstein I. 2005. Down syndrome screening in multiple pregnancies. Obstet Gynecol Clin North Am 32: 81-96, ix

7. Gagnon A, Audibert F. 2014. Prenatal screening and diagnosis of aneuploidy in multiple pregnancies. Best Pract Res Clin Obstet Gynaecol 28: 285-94

8. Malone FD, Canick JA, Ball RH, Nyberg DA, Comstock CH, Bukowski R, Berkowitz RL, Gross SJ, Dugoff L, Craigo SD, Timor-Tritsch IE, Carr SR, Wolfe HM, Dukes K, Bianchi DW, Rudnicka AR, Hackshaw AK, Lambert-Messerlian G, Wald NJ, D'Alton ME, First, Second-Trimester Evaluation of Risk Research C. 2005. Firsttrimester or second-trimester screening, or both, for Down's syndrome. $N$ Engl J Med 353: 2001-11

9. Cahill AG, Macones GA, Stamilio DM, Dicke JM, Crane JP, Odibo AO. 2009. Pregnancy loss rate after mid-trimester amniocentesis in twin pregnancies. Am J Obstet Gynecol 200: 257 e1-6

10. Gil MM, Quezada MS, Revello R, Akolekar R, Nicolaides KH. 2015. Analysis of cellfree DNA in maternal blood in screening for fetal aneuploidies: updated metaanalysis. Ultrasound Obstet Gynecol 45: 249-66

11. Peters KF, Saltsman BM, Petrill SA. 2006. Twin gestation pregnancies: genetic counseling and testing experience.J Genet Couns 15: 119-27

12. Holmes A, Jauniaux E. 2004. Prospective study of parental choice for aneuploidy screening in assisted conception versus spontaneously conceived twins. Reprod Biomed Online 8: 243-5 
13. Friel LA, Czerwinski JL, Singletary CN. 2014. The impact of noninvasive prenatal testing on the practice of maternal-fetal medicine. Am J Perinatol 31: 759-64

14. Allyse M, Sayres LC, Goodspeed TA, Cho MK. 2014. Attitudes towards noninvasive prenatal testing for aneuploidy among US adults of reproductive age.J Perinatol 34: 429-34

15. Tversky A, Kahneman D. 1974. Judgment under Uncertainty: Heuristics and Biases. Science 185: 1124-31

16. Pivetti M, Melotti G. 2013. Prenatal genetic testing: an investigation of determining factors affecting the decision-making process.J Genet Couns 22: 7689 


\section{APPENDIX A.}

1. How do you feel about prenatal genetic screening (first trimester screening, quad screening, NIPT, cell-free DNA) in your current pregnancy?

Strongly against

1

2. How do you feel about prenatal genetic testing (chorionic villus sampling-CVS, amniocentesis) in your current pregnancy?

Strongly against

1

2

3

Strongly in favor of

4

5

3. Does your decision to undergo or not undergo prenatal genetic screening/testing agree with your feelings prior to the genetic counseling appointment?

Yes

No

Additional comments:

4. If this were a singleton pregnancy, what would your decision about prenatal genetic screening/ testing have been?

Same

Different

If different, in what way?:

I don't know

5. What factors influenced your decision-making? Choose all that apply:

$\square$ Partner/Spouse

Other family member

Doctor

Genetic Counselor

Religious beliefs

Risk for pregnancy loss

Chance of chromosome condition $\square$ Gaining reassurance about pregnancy

$\square$ Screening/testing in prior pregnancy

Being pregnant with twins

$\square$ Difficulty becoming pregnant

I don't know

$\square$ None of the above

Other:

\section{For Office Use Only:}

Date:

Age:__ G__ P

Ethnicity: Caucasian Hispanic

Asian African American

Other:

\section{ART?: IVF IUI OI/Clomid \\ PGS PGD Donor egg: $Y / N$ \\ Other:}

Offered Screens/Tests: FTS Quad NIPT

CVS Amnio

\begin{tabular}{ll} 
Accepted Screens/Tests: & FTS \\
& \multicolumn{1}{c}{ Quad NIPT } \\
Indication: & Low Risk \\
& AMA \\
& Positive FTS \\
& Positive Quad Screen \\
& Positive Family History \\
& Positive Carrier Screen \\
& Ultrasound Abnormality
\end{tabular}




\title{
APPENDIX B.
}

Questions:

\author{
Interview Guide
}

- Tell me about your experience getting pregnant.

○ Probes

- What was your reaction to learning that you were pregnant with twins?

- Was this a positive or difficult experience?

- How did it affect your family and relationships?

- Tell me about your experience with genetic counseling.

- Probes

- What were your feelings toward/impressions of prenatal genetic screening and testing before the session?

- Concerns?

- Did any prior feelings change after talking to the genetic counselor?

- How? Why?

- Had you heard of prenatal genetic screening or testing prior to the appointment?

- Did you pursue this option in a prior pregnancy?

- Tell me about how you came to a decision about prenatal screening or testing.

○ Probes

- Do you think you would have felt the same way and made the same decision if this were a singleton pregnancy?

- Why did you choose___ over other options offered?

- What factors influenced your decision?

- Other than yourself, who played an important role in your decision?

- Is there any other information you would like to share about carrying twins, having genetic counseling, screening or testing? 


\section{VITA}

Kathryn Marie Reese was born in Oklahoma City, Oklahoma on July 20, 1993, the daughter of Stephanie Patrice Reese and Eric Gerard Reese. After completing her work at Round Rock High School, Round Rock, Texas in 2011, she entered The University of Texas at Austin, Austin, Texas. She received the degree of Bachelor of Sciences with a major in Human Biology from The University of Texas in May 2015. In August of 2015 she entered The University of Texas MD Anderson Cancer Center UTHealth Graduate School of Biomedical Sciences.

\section{Permanent address:}

15040 Jacks Pond Road

Austin, Texas 78728 